\section{Exacerbations in non-COPD patients: truth or myth}

We read with great interest the article by Tan et $\mathrm{al}^{1}{ }^{1}$ whereby they have discussed the occurrence of exacerbation-like events in patients without COPD. The basic concept of the study needs debate and clarification.

The authors have used the terms 'non-COPD patients' and 'exacerbation like event' to mention the group of patients who didn't fulfil the spirometric criteria for COPD. Without mentioning its causes, this non-COPD group with chronic respiratory symptoms seems to be a new disease process. Here, it should be clarified that this non-COPD group is not a distinct aetiological entity. Rather, these chronic symptoms are the result of any of the undetected upper and lower respiratory tract diseases, like bronchitis, bronchiectasis, postnasal drip, chronic pharyngitis, chronic cough due to Gastro-oesophageal Reflux Disease (GERD), early COPD, mild asthma, heart failure, and so on, which were not properly investigated and, hence, might have become chronic. ${ }^{2}$ Also, inclusion of acute conditions, like pneumonia, pneumothorax and using the term, exacerbation, for these patients in the non-COPD group needs explanation. Without getting a broncho-provocative challenge test, it is likely that a good number of subjects in non-COPD group might actually have asthma. The significant economic and healthcare burden of this non-COPD group is hence obvious and not surprising. ${ }^{3}$ In view of diverse aetiologies in a non-COPD group, it is difficult to justify the use of the term 'exacerbation like events' for this varied patient group, and compare their symptom spurts with those of acute exacerbations of COPD.

These terminologies 'non-COPD patients' and 'exacerbation like event' should be used with caution, as it may, inadvertently, lead to the creation of a separate disease group, creating confusion about the correct terminology. Moreover, being easy to label, these terms are prone to be misused for all non-COPD patients, without subjecting them to detailed investigations.

It would be useful if authors exclude known causes of chronic symptoms in
non-COPD patients before evaluating and comparing them with COPD. Proper diagnosis and categorisation of these non-COPD patients could help in proper management, as well as may change the course of their disease.

Deepak Aggarwal, ${ }^{1}$ Alkesh Kumar Khurana ${ }^{2}$

${ }^{1}$ Department of Pulmonary Medicine, Government Medical College \& Hospital, Chandigarh, India ${ }^{2}$ Department of Pulmonary Medicine, All India Institute of Medical Sciences, Bhopal, Madhya Pradesh, India

Correspondence to Dr Alkesh Kumar Khurana, Department of Pulmonary Medicine, All India Institute of Medical Sciences, Bhopal, Madhya Pradesh 462024, India; lungcancer@rediffmail.com

Competing interests None.

Provenance and peer review Not commissioned; externally peer reviewed.

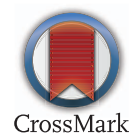

To cite Aggarwal D, Khurana AK. Thorax 2014;69:1050.

Received 19 May 2014

Accepted 12 June 2014

Published Online First 26 June 2014

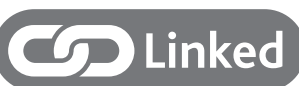

- http://dx.doi.org/10.1136/thoraxjnl-2013-205048

http://dx.doi.org/10.1136/thoraxjnl-2014-205889

Thorax 2014;69:1050.

doi:10.1136/thoraxjnl-2014-205763

\section{REFERENCES}

1 Tan WC, Baurbeau J, Hernandez P, et al. Exacerbation like respiratory symptoms in individuals without chronic obstructive pulmonary disease: results from a population based study. Thorax 2014;69:709-17.

2 Irwin RS, Madison JM. The diagnosis and treatment of cough. N Engl J Med 2013;343:1715-21.

3 GINA: GINA Report:Global Strategy for Asthma Management and Prevention.Global Initiative for Asthma 2014. http://www.ginasthma.org/ (accessed 17 May 2014). 